\title{
A novel EIF4ENIF1 mutation associated with a diminished ovarian reserve and premature ovarian insufficiency identified by whole-exome sequencing
}

\author{
Minying Zhao ${ }^{1 * \dagger}$, Fan Feng ${ }^{2+}$, Chunfang $\mathrm{Chu}^{3}$, Wentao Yue ${ }^{4}$ and Lin $\mathrm{Li}^{4^{*}}$ (D)
}

\begin{abstract}
Background: To dissect the genetic causes underlying diminished ovarian reserve (DOR) and premature ovarian insufficiency (POI) within a family.

Methods: Whole-exome sequencing of the proband was performed and DOR and Sanger sequencing was carried out to validate presence of the variant in the proband and her mother. In silico algorithms were used to analyze the mutational effect of the variant. PSIPRED (PSI-blast based secondary structure PREDiction) was used for predicting mutated protein secondary structures.

Results: Using whole-exome sequencing, we found that the proband carries the mutation c.2525A > C;p.Q842P in EIF4ENIF, a POI-related gene. Through Sanger sequencing, we found that the proband's mother also carries the same mutation. Online bioinformatics analysis suggests that the mutation is a pathogenic mutation. Secondary structural biology prediction analysis indicates that the mutation either causes the destruction of the a-helical structure around the mutation site or reduces the a-helix.

Conclusions: This mutation is the second novel mutation of EIF4ENIF1 that has been identified in POI patients. This study thus provides a theoretical basis for POI genetics and POI clinical genetic counseling.
\end{abstract}

Keywords: Diminished ovarian reserve, Whole-exome sequencing, EIF4ENIF1, Premature ovarian failure

\section{Background}

Ovarian development consists of a series of elaborate developmental processes, including primordial germ cell migration and development, meiosis, and folliculogenesis. The ovarian reserve is related to the number and quality of the remaining oocytes. As such, diminished ovarian reserve (DOR) is used to describe women of reproductive age with regular menstruation cycles whose response to ovarian stimulation or reproductive capacity is less than that of women of comparable age. DOR can be identified based on an abnormal ovarian reserve test (antral

\footnotetext{
*Correspondence: zhaominying8866@163.com; linlithu@163.com

${ }^{+}$Minying Zhao and Fan Feng contributed equally to this work.

'Department of Reproductive Medicine, The First Hospital of Shijiazhuang, 36 Fanxi Road, Shijiazhuang 050011, Hebei, China

${ }^{4}$ Central Laboratory, Beijing Obstetrics and Gynecology Hospital, Capital

Medical University, Chaoyang, Beijing 100026, China

Full list of author information is available at the end of the article
}

follicular count $<5-7$ follicles or anti-Mullerian hormone $<0.5-1.1 \mathrm{ng} / \mathrm{mL}$ ) [1]. DOR is different from premature ovarian insufficiency (POI), which is characterized by at least 4 months of amenorrhea or oligomenorrhea, elevated follicle-stimulating hormone (FSH) levels (> $25 \mathrm{IU} / \mathrm{L}$ ), and low estradiol. The prevalence of POI is $\sim 1 \%$ in the general population [2]. Several factors, including chromosomal abnormalities, Fragile X premutations, point mutations, autoimmune disorders, and medical or surgical interventions, contribute to the onset of POI. However, the causes of POI for most women remain unclear, although unexplored genetic factors may partially explain some POI cases. POI and DOR share a common pathogenesis and are both related to abnormal ovarian reserves. We thus hypothesize that DOR may represent an early stage and partial manifestation of POI.

(c) The Author(s). 2019 Open Access This article is distributed under the terms of the Creative Commons Attribution 4.0 International License (http://creativecommons.org/licenses/by/4.0/), which permits unrestricted use, distribution, and reproduction in any medium, provided you give appropriate credit to the original author(s) and the source, provide a link to the Creative Commons license, and indicate if changes were made. The Creative Commons Public Domain Dedication waiver (http://creativecommons.org/publicdomain/zero/1.0/) applies to the data made available in this article, unless otherwise stated. 
From a genetic point of view, POI is a heterogeneous disease [3]. The pathogenic molecular mechanism of POI has been thought involve mutations in genes involved in several developmental processes, including primordial germ cell survival [4], DNA repair and meiotic recombination [5-12], oocyte transcription and translational control during folliculogenesis [13-20], granulosa cell development [21-25], and oocyte mitochondrial function [26, 27].

EIF4ENIF1, or eukaryotic translation initiation factor $4 \mathrm{E}$ nuclear import factor 1 , is a nucleocytoplasmic shuttle protein that is enriched in P-bodies for transport of the translation initiation factor eIF4E. In addition, EIF4ENIF1 can competitively prevent the productive binding of eIF4E to eIF4G, thereby reducing protein synthesis by regulating ribosomal delays through interfering with the interaction between eIF4E and eIF4G [28]. EIF4ENIF1 can thus control access of the $5^{\prime}$ cap of specific mRNAs by ribosomes and mediate translational repression [29, 30]. Previous studies have shown that EIF4ENIF1 is a part of a large CPEB (Cytoplasmic Polyadenylation Element Binding) translation inhibitor RNP (RiboNucleoProtein) complex in Xenopus laevis oocytes [31]. In mouse oocytes, EIF4ENIF1 is essential for breakdown of the nuclear envelope and the resumption of meiosis [32]. Moreover, in a large French-Canadian family [20], seven women affected with POI possessed a heterozygous premature stop codon (Ser429*) in EIF4ENIF1 that was not present in the unaffected members, suggesting a dominant mode of inheritance of POIcausing EIF4ENIF1 mutations [20]. EIF4ENIF1 is therefore a good candidate gene for investigation to determine its role in POI and ovarian reserve abnormalities.

In this study, we recruited a family in which the proband was diagnosed with DOR and whose mother was a POI patient. We then used whole-exome sequencing to dissect the genetic causes underlying DOR in this family.

\section{Methods \\ Patients}

All procedures involving human participants were performed in accordance with the ethical standards of the Ethics Committee of the First Hospital of Shijiazhuang and the 1964 Helsinki declaration and its later amendments. Written informed consent was obtained from each participant. The proband (Fig. 1a, II-1) with DOR was recruited from the First Hospital of Shijiazhuang. The proband developed DOR in 2018 at the age of 28. The hormone levels of the proband were as follows: folliclestimulating hormone, $8.71 \mathrm{IU} / \mathrm{L}$; luteinizing hormone, $2.93 \mathrm{IU} / \mathrm{L}$; estradiol, $62 \mathrm{pmol} / \mathrm{L}$; testosterone, $0.48 \mathrm{nmol} / \mathrm{L}$; prolactin, $8.32 \mathrm{ng} / \mathrm{mL}$; and anti-Mullerian hormone, 1.67 $\mathrm{ng} / \mathrm{mL}$. Ultrasound imaging of the left (Fig. 1b) and right (Fig. 1c) ovaries showed no antral follicles and one antral

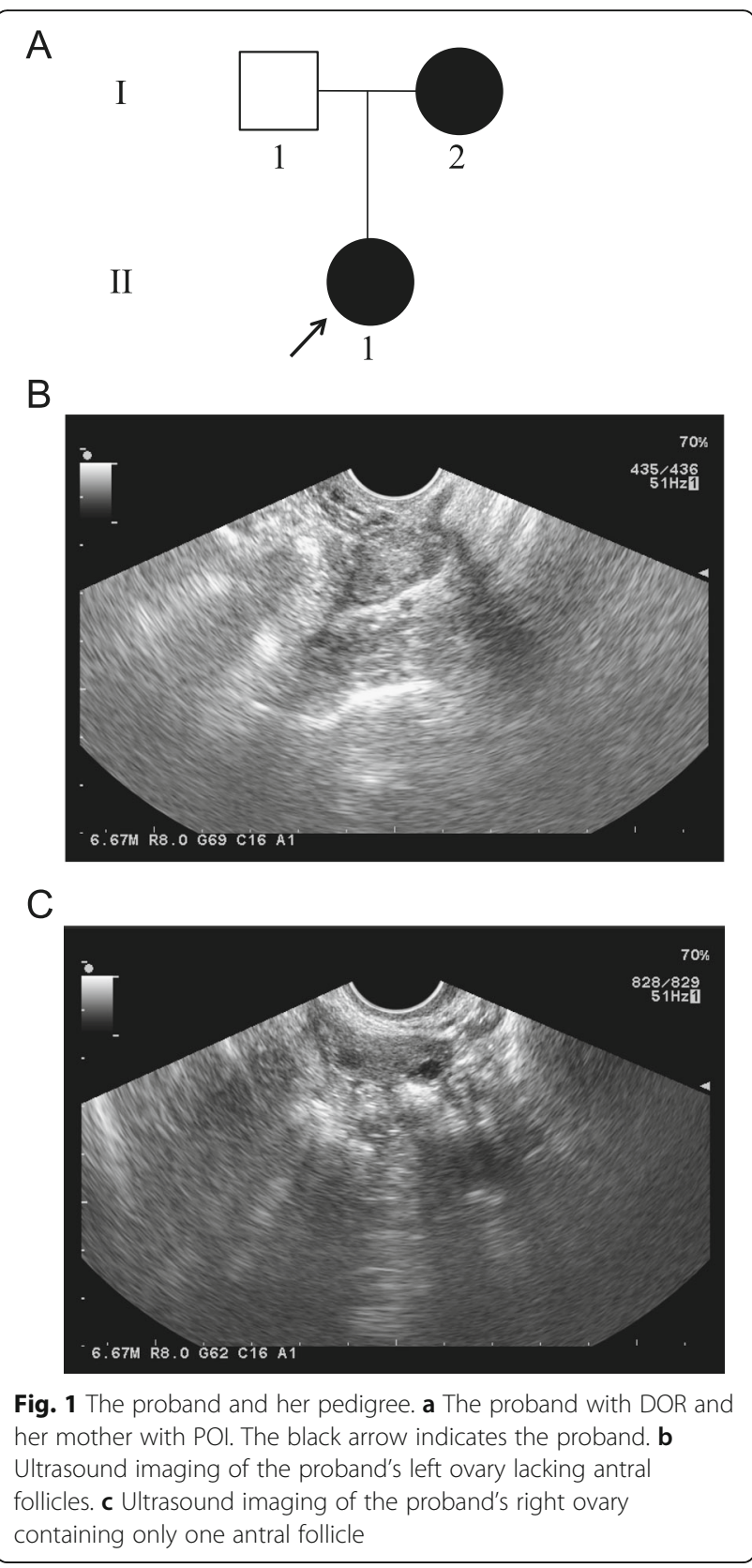

follicle, respectively. In addition, the proband's mother (Fig. 1a, I-2) developed amenorrhea at the age of 39.

\section{Whole-exome sequencing and data analysis}

Genomic DNA was extracted from peripheral blood using a QIAamp DNA Mini Kit (Qiagen, Valencia, CA, USA). Whole-exome sequencing (WES) was performed as previously described [33]. A two-step process was used for filtering variants. First, rare and novel variants (minor allele frequency $<1 \%$ ) were selected. Minor allele frequencies were analyzed based on data in the Exome Aggregation Consortium (ExAC, http://exac.broadinstitute.org/), 1000 Genomes (http://browser.1000genomes.org/index.html), 
Genome Aggregation Database (gnomAD, http://gnomad. broadinstitute.org/), and ESP6500 (http://evs.gs.washington. $\mathrm{edu} / \mathrm{EVS} /$ ) databases. Second, only frameshift, nonsense, missense, and splicing-site variants were retained.

\section{Sanger sequencing validation}

WES results were validated using Sanger sequencing. For the EIF4ENIF1 (c.2525A > C:p.Q842P) variant, forward (5'ATGAAGCAAACGATGGTTCC-3') and reverse (5'TAGGGGATTGACTGGATTGG-3') primers were used for PCR amplification and Sanger sequencing. DNA products were evaluated using electrophoresis with an ABI 3730 XL DNA sequencer (Applied Biosystems, Bedford, MA).

\section{Protein secondary structure predictions}

PSIPRED [34] was used to predict protein secondary structures. PSIPRED generates secondary structure predictions using up to four feed-forward neural networks and PSIBLAST outputs, which are then used to find related sequences and build a position-specific scoring matrix. The generation of a sequence profile is performed by PSIBLAST then normalized by PSIPRED. The prediction of an initial secondary structure is done by a neural network, while a second neural network is used to filter the structure predicted by the first network. PSIPRED then predicts the secondary structure with the highest score.

\section{Results}

WES analysis of the proband and sanger sequencing validation

The proband was diagnosed with DOR, while her mother was diagnosed with POI, suggesting that genetic factors may play an important role in observed ovarian disfunction. WES was performed to analyze the potential genetic causes of proband DOR. WES data was filtered to retain frameshift, splice-site, missense, and nonsense variants while excluding variants with allele frequencies $>1 \%$ in the whole-exome or whole-genome databases (ExAC, gnomAD, ESP6500, and 1000 Genomes). This led to identification of the variant c.2525A > C;p.Q842P in the POI-related gene EIF4ENIF1, which had previously been associated with POI in a study analyzing a large pedigree [20]. The proband variant c.2525A $>C$ was confirmed using Sanger sequencing (Fig. 2a) and appears to have been inherited from her mother, not her father (Fig. 2a).

\section{In silico analysis of the EIF4ENIF1 variant}

By performing sequence alignment analysis, we found that Q842 is highly conserved across species ranging from humans to zebrafish (Fig. 2b), suggesting that Q842 plays an important role in EIF4ENIF1 protein function. The allele frequency of c.2525A $>\mathrm{C}$ is $0.0000084,0.00001634$, 0 , and, 0 in the ExAC, gnomAD, ESP6500 and 1000

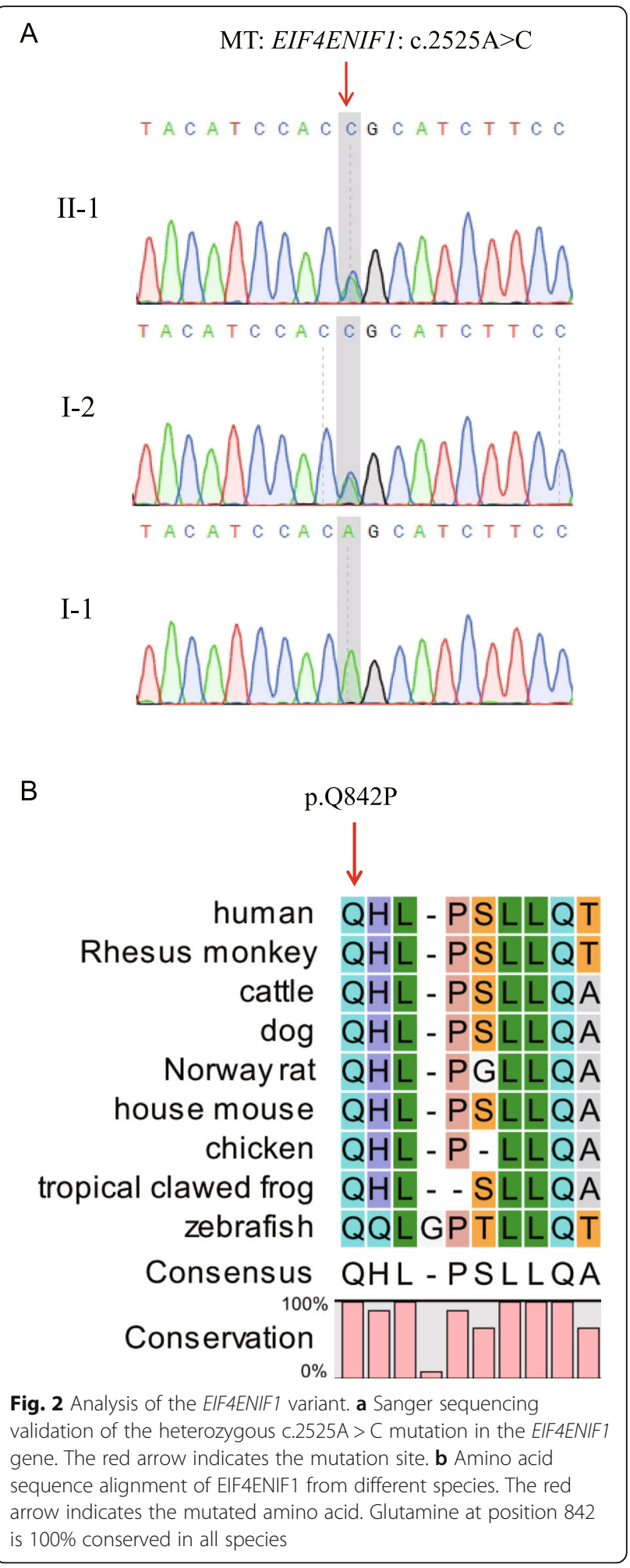

Genomes databases, respectively (Table 1 ). This suggests that the c. $2525 \mathrm{~A}>\mathrm{C}$ variant is very rarely found in the general population. Five of six online prediction tools for mutation effects suggest that Q842P is a disease-causing mutation (Table 1). Moreover, analysis using the 
Table 1 In silico analysis of EIF4ENIF1 mutation

\begin{tabular}{|c|c|c|c|c|c|c|c|c|c|c|c|}
\hline Variants & $\begin{array}{l}\text { Amino } \\
\text { acid } \\
\text { change }\end{array}$ & Polyphen-2 $^{\mathrm{a}}$ & $\mathrm{SIFT}^{\mathrm{b}}$ & PROVEAN ${ }^{c}$ & $\begin{array}{l}\text { Mutation } \\
\text { Taster }^{d}\end{array}$ & SNPs\&GO & $\begin{array}{l}\text { FATHMM- } \\
\text { MKL }^{f}\end{array}$ & gnomADg & EXAC $^{h}$ & $\begin{array}{l}1000 \\
\text { Genomes }\end{array}$ & ESP6500 \\
\hline $\begin{array}{l}\text { C. } 2525 A> \\
C\end{array}$ & p. Q842P & $\begin{array}{l}\text { Probably } \\
\text { damaging } \\
(0.996)\end{array}$ & $\begin{array}{l}\text { Damaging } \\
(0.002)\end{array}$ & $\begin{array}{l}\text { Deleterious } \\
(-3.21)\end{array}$ & $\begin{array}{l}\text { Disease } \\
\text { causing } \\
(0.999)\end{array}$ & $\begin{array}{l}\text { Neutral } \\
(0.247)\end{array}$ & $\begin{array}{l}\text { Damaging } \\
(0.983)\end{array}$ & 0.00001634 & 0.0000084 & 0 & 0 \\
\hline
\end{tabular}

aPolyphen-2. Prediction Scores range from 0 to 1 with high scores indicating probably or possibly damaging

${ }^{b}$ SIFT, i.e., Sorting Intolerant From Tolerant. Scores vary between 0 and 1. Variants with scores close or equal to 0 are predicted to be damaging

CPROVEAN. Variants with scores lower than -2.5 (cutoff) are predicted to be deleterious

${ }^{\mathrm{d}}$ Mutation Taster. The probability value is the probability of the prediction, i.e., a value close to 1 indicates a high 'security' of the prediction

eSNPs\&GO. Probability: Disease probability (if $>0.5$ mutation is predicted Disease)

fFATHMM-MKL. Values above 0.5 are predicted to be deleterious, while those below 0.5 are predicted to be neutral or benign

${ }^{9}$ Frequency of variation in total of gnomAD database

${ }^{\mathrm{h}}$ Frequency of variation in total of ExAC database

'Frequency of variation in 1000 Genomes database

'Frequency of variation in ESP6500 database

Constraint Metrics Z score for missense variation suggests that EIF4ENIF1 gene is intolerant to variation, with $\mathrm{z}=$ 1.95 and $\mathrm{pLI}=1.00$ (http://exac.broadinstitute.org/gene/ ENSG00000184708). This indicates that the EIF4ENIF1 gene has fewer variants than expected and that the heterozygous variant found in EIF4ENIF1 may be pathogenic. Therefore, in summary, all in silico analyses performed predicts that the c.2525A > C;p.Q842P variant may be a pathogenic mutation associated with DOR and POI.

\section{Modeling of the secondary structure of EIF4ENIF1 Q842P}

The structure of a protein is extremely important for its biological function. We therefore predicted the secondary structure of EIF4ENIF1 (721-900aa) using PSIPRED 4.0.1 (Fig. 3a) and found that the Q842 site was crucial for $\alpha$ helix formation (red cylinder). Q842 is located at the beginning of the helix and sequence conservation analysis showed that Q842 is conserved across species. These results thus illustrate the importance of $Q$ in the formation of EIF4ENIF1 secondary structure and function. In the variant detected in our study, Q was mutated to P. By using computer-based calculations, we identified two possible results of this mutation (Fig. 3b). This mutation may result in the conversion of the $\alpha$-helix in the wild type protein to a random coil or may change the length of the $\alpha$-helix. $P$ is thus considered problematic for helix

\section{A}

EIF4ENIF1: 721-900aa
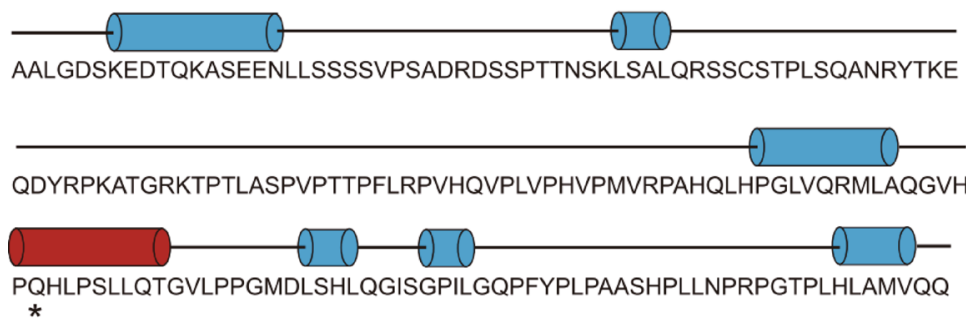

B

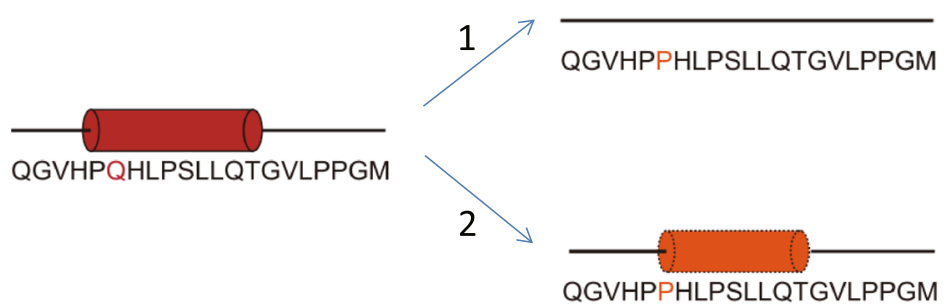

Fig. 3 Structural analysis of the variant. a Secondary structure prediction of EIF4ENIF1 by PSIPRED 4.0.1. The straight line represents a coil and the cylinder represents an a-helix. The star indicates the Q842. b Modeling of the secondary structure of EIF4ENIF1 Q842P. The upper image shows how Q842P could change the a-helix into a coil while the lower image shows how Q842P may change the length or form of the a-helix 
formation, especially when present in the middle of the sequence. Due to the molecular structure of proline, the Q842P mutation changes the structural stability of the $\alpha$ helix. Such structural changes can then affect proteinprotein interactions or signal transduction, leading to misregulation of normal gene transcription.

\section{Discussion}

In this study, we identified an EIF4ENIF1 heterozygous variant in a patient with DOR using WES. Moreover, we found that this patient inherited the variant from her mother, who suffers from POI. Bioinformatics analysis suggests that the variant c.2525A > C;p.Q842P may be a pathogenic allele. Additionally, secondary structure modeling suggests that Q842P may change the original $\alpha$-helix structure.

The EIF4ENIF1 mutation found in this study is a heterozygous mutation, in line with its dominant inheritance. The genetic mode of inheritance of POI in this study is consistent with that described in the previously published literature [20]. Two possible mechanisms can be used to explain the presence of this mutation: haploinsufficiency or the dominant-negative effect. However, previously published studies [20] indicate that the haploinsufficiency mechanism is more likely since these studies found a premature stop codon (p.Ser429*) in a variant of EIF4ENIF1 while our study identified a point mutation (p.Q842P) in EIF4ENIF1. Since we have not done the relevant functional experiments, we cannot determine whether the effect of this point mutation completely eliminates protein function. However, the haploinsufficiency mechanism is more likely the cause of the effects of heterozygous EIF4ENIF1 mutations since the EIF4ENIF1 protein has not been reported to function as a dimer. In general, when a protein can function as a dimer, the mutation found in that protein will have a dominant negative effect. EIF4ENIF1 inhibits protein translation by binding to EIF4E [35], decreases in levels of EIF4ENIF1 lead to partial decreases in EIF4E inhibition, which may result in increased protein translation and enhanced mRNA stability.

\section{Conclusions}

In conclusion, our study identified a rare mutation of the EIF4ENIF1 gene in a family exhibiting DOR and POI. Online bioinformatics analysis suggests that this mutation is a pathogenic mutation. Moreover, secondary structural biology prediction analysis suggests that this mutation either causes the destruction of the $\alpha$-helical structure around the mutation site or a reduction in $\alpha$ helix length. This mutation is the second novel mutation of EIF4ENIF1, identified in POI patients. This study therefore provides new information on POI genetics and a novel gene locus for use in genetic counseling for POI and related diseases.

\section{Acknowledgements}

We thank the patients for participating in this study.

\section{Authors' contributions}

LL and CC performed WES data analysis and in silico analysis, FF performed the molecular modeling analysis, samples from the patient were collected by $M Z$ and $L L$ and $W Y$ designed the experiments and wrote the manuscript.All authors read and approved the final manuscript

\section{Funding}

This study was supported by the National Natural Science Foundation of China (81701405).

\section{Availability of data and materials}

The datasets used and/or analyzed during the current study are available from the corresponding author upon reasonable request.

\section{Ethics approval and consent to participate}

This study has been approved by the Ethics Committee of The First Hospital of Shijiazhuang and is in accordance with the 1964 Helsinki Declaration and its later amendments. Each participant in this study signed an informed consent form to participate in this study.

\section{Consent for publication}

Each participant in this study signed an informed consent form for publication of all of the participants' clinical details.

\section{Competing interests}

All authors read and approved the final manuscript

\section{Author details}

${ }^{1}$ Department of Reproductive Medicine, The First Hospital of Shijiazhuang, 36 Fanxi Road, Shijiazhuang 050011, Hebei, China. ${ }^{2}$ Department of Basic Medical Sciences, School of Medicine, Tsinghua University, Haidian, Beijing 100084,

China. ${ }^{3}$ Department of Gynecology, Beijing Obstetrics and Gynecology Hospital, Capital Medical University, Chaoyang, Beijing 100026, China.

${ }^{4}$ Central Laboratory, Beijing Obstetrics and Gynecology Hospital, Capital Medical University, Chaoyang, Beijing 100026, China.

Received: 24 July 2019 Accepted: 26 November 2019

\section{1.}

\section{References}

1. Cohen J, Chabbert-Buffet N, Darai E. Diminished ovarian reserve, premature ovarian failure, poor ovarian responder--a plea for universal definitions. J Assist Reprod Genet. 2015:32(12):1709-12.

2. Webber L, Davies M, Anderson R, Bartlett J, Braat D, Cartwright B, Cifkova R, de Muinck K-SS, Hogervorst E, Janse F, Liao L, Vlaisavljevic V, Zillikens C, Vermeulen N. ESHRE guideline: management of women with premature ovarian insufficiency. Hum Reprod. 2016:31(5):926-37.

3. Jiao X, Ke H, Qin Y, Chen ZJ. Molecular genetics of premature ovarian insufficiency. Trends Endocrinol Metab. 2018;29(11):795-807.

4. Wu X, Wang B, Dong Z, Zhou S, Liu Z, Shi G, Cao Y, Xu Y. A NANOS3 mutation linked to protein degradation causes premature ovarian insufficiency. Cell Death Dis. 2013:4:e825.

5. Caburet S, Arboleda VA, Llano E, Overbeek PA, Barbero JL, Oka K, Harrison W, Vaiman D, Ben-Neriah Z, Garcia-Tunon I, Fellous M, Pendas AM, Veitia RA Vilain E. Mutant cohesin in premature ovarian failure. N Engl J Med. 2014; 370(10):943-9.

6. Qin Y, Guo T, Li G, Tang TS, Zhao S, Jiao X, Gong J, Gao F, Guo C, Simpson $J$, Chen ZJ. CSB-PGBD3 mutations cause premature ovarian failure. PLoS Genet. 2015:11(7):e1005419.

7. Wood-Trageser MA, Gurbuz F, Yatsenko SA, Jeffries EP, Kotan LD, Surti U, Ketterer DM, Matic J, Chipkin J, Jiang HY, Trakselis MA, Topaloglu AK, Rajkovic A. MCM9 mutations are associated with ovarian failure, short stature, and chromosomal instability. Am J Hum Genet. 2014;95(6):754-62

8. Carlosama C, Elzaiat M, Patino LC, Mateus HE, Veitia RA, Laissue P. A homozygous donor splice-site mutation in the meiotic gene MSH4 causes primary ovarian insufficiency. Hum Mol Genet. 2017;26(16):3161-6. 
9. Guo T, Zhao S, Chen M, Li G, Jiao X, Wang Z, Zhao Y, Qin Y, Gao F, Chen ZJ. Mutations in MSH5 in primary ovarian insufficiency. Hum Mol Genet. 2017; 26(8):1452-7.

10. Turchetti D, Zuntini R, Tricarico R. BRCA2 in ovarian development and function. N Engl J Med. 2019;380(11):1086-7.

11. Caburet S, Todeschini AL, Petrillo C, Martini E, Farran ND, Legois B, Livera G, Younis JS, Shalev S, Veitia RA. A truncating MEIOB mutation responsible for familial primary ovarian insufficiency abolishes its interaction with its partner SPATA22 and their recruitment to DNA double-strand breaks. EBioMedicine. 2019;42:524-31.

12. Al-Agha AE, Ahmed IA, Nuebel E, Moriwaki M, Moore B, Peacock KA, Mosbruger T, Neklason DW, Jorde LB, Yandell M, Welt CK. Primary ovarian insufficiency and Azoospermia in carriers of a homozygous PSMC3IP stop gain mutation. J Clin Endocrinol Metab. 2018;103(2):555-63.

13. Zhao H, Chen ZJ, Qin YY, Shi YH, Wang S, Choi Y, Simpson JL, Rajkovic A. Transcription factor FIGLA is mutated in patients with premature ovarian failure. Am J Hum Genet. 2008;82(6):1342-8.

14. Chen B, Li L, Wang J, Li T, Pan H, Liu B, Zhou Y, Cao Y, Wang B. Consanguineous familial study revealed biallelic FIGLA mutation associated with premature ovarian insufficiency. J Ovarian Res. 2018;11(1):48.

15. Qin Y, Choi Y, Zhao H, Simpson JL, Chen ZJ, Rajkovic A. NOBOX homeobox mutation causes premature ovarian failure. Am J Hum Genet. 2007;81(3):576-81.

16. Li L, Wang B, Zhang W, Chen B, Luo M, Wang J, Wang X, Cao Y, Kee K. A homozygous NOBOX truncating variant causes defective transcriptional activation and leads to primary ovarian insufficiency. Hum Reprod. 2017; 32(1):248-55.

17. Wang Q, Li D, Cai B, Chen Q, Li C, Wu Y, Jin L, Wang X, Zhang X, Zhang F. Whole-exome sequencing reveals SALL4 variants in premature ovarian insufficiency: an update on genotype-phenotype correlations. Hum Genet. 2019;138(1):83-92.

18. Franca MM, Han X, Funari MFA, Lerario AM, Nishi MY, Fontenele EGP, Domenice S, Jorge AAL, Garcia-Galiano D, Elias CF, Mendonca BB. Exome sequencing reveals the POLR3H gene as a novel cause of primary ovarian insufficiency. J Clin Endocrinol Metab. 2019;104(7):2827-41.

19. Tucker EJ, Jaillard S, Grover SR, van den Bergen J, Robevska G, Bell KM, Sadedin S, Hanna C, Dulon J, Touraine P, Sinclair AH. TP63-truncating variants cause isolated premature ovarian insufficiency. Hum Mutat. 2019; 40(7):886-92.

20. Kasippillai T, MacArthur DG, Kirby A, Thomas B, Lambalk CB, Daly MJ, Welt CK. Mutations in elF4ENIF1 are associated with primary ovarian insufficiency. J Clin Endocrinol Metab. 2013;98(9):E1534-9.

21. Li L, Zhou X, Wang X, Wang J, Zhang W, Wang B, Cao Y, Kee K. A dominant negative mutation at the ATP binding domain of AMHR2 is associated with a defective anti-Mullerian hormone signaling pathway. Mol Hum Reprod. 2016;22(9):669-78.

22. De Baere E, Lemercier B, Christin-Maitre S, Durval D, Messiaen L, Fellous M, Veitia R. FOXL2 mutation screening in a large panel of POF patients and XX males. J Med Genet. 2002;39(8):e43.

23. Huang K, Dang Y, Zhang P, Shen C, Sui X, Xia G, Qin Y, Jiao X, Wang C, Huo $R$, Chen ZJ. CAV1 regulates primordial follicle formation via the Notch2 signalling pathway and is associated with premature ovarian insufficiency in humans. Hum Reprod. 2018;33(11):2087-95.

24. Lourenco D, Brauner R, Lin L, De Perdigo A, Weryha G, Muresan M, Boudjenah R, Guerra G, Maciel-Guerra AT, Achermann JC, McElreavey K, Bashamboo A. Mutations in NR5A1 associated with ovarian insufficiency. N Engl J Med. 2009;360(12):1200-10.

25. Patino LC, Beau I, Morel A, Delemer B, Young J, Binart N, Laissue P. Functional evidence implicating NOTCH2 missense mutations in primary ovarian insufficiency etiology. Hum Mutat. 2019;40(1):25-30.

26. Chen B, Li L, Wang J, Zhou Y, Zhu J, Li T, Pan H, Liu B, Cao Y, Wang B. Identification of the first homozygous POLG mutation causing nonsyndromic ovarian dysfunction. Climacteric. 2018;21(5):467-71.

27. Hamatani M, Jingami N, Tsurusaki $Y$, Shimada S, Shimojima K, Asada-Utsugi M, Yoshinaga K, Uemura N, Yamashita H, Uemura K, Takahashi R, Matsumoto N, Yamamoto T. The first Japanese case of leukodystrophy with ovarian failure arising from novel compound heterozygous AARS2 mutations. J Hum Genet. 2016;61(10):899-902.

28. Sonenberg N, Hinnebusch AG. Regulation of translation initiation in eukaryotes: mechanisms and biological targets. Cell. 2009;136(4):731-45.

29. Kamenska A, Simpson C, Standart N. elF4E-binding proteins: new factors, new locations, new roles. Biochem Soc Trans. 2014:42(4):1238-45.
30. Kamenska A, Simpson C, Vindry C, Broomhead H, Benard M, Ernoult-Lange M, Lee BP, Harries LW, Weil D, Standart N. The DDX6-4E-T interaction mediates translational repression and P-body assembly. Nucleic Acids Res. 2016:44(13):6318-34.

31. Minshall N, Reiter MH, Weil D, Standart N. CPEB interacts with an ovaryspecific elF4E and 4E-T in early Xenopus oocytes. J Biol Chem. 2007;282(52): 37389-401.

32. Pfender S, Kuznetsov V, Pasternak M, Tischer T, Santhanam B, Schuh M. Live imaging RNAi screen reveals genes essential for meiosis in mammalian oocytes. Nature. 2015;524(7564):239-42.

33. Sha YW, Sha YK, Ji ZY, Mei LB, Ding L, Zhang Q, Qiu PP, Lin SB, Wang X Li P, Xu X, Li L. TSGA10 is a novel candidate gene associated with acephalic spermatozoa. Clin Genet. 2018;93(4):776-83.

34. McGuffin LJ, Bryson K, Jones DT. The PSIPRED protein structure prediction server. Bioinformatics. 2000;16(4):404-5.

35. Ferraiuolo MA, Basak S, Dostie J, Murray EL, Schoenberg DR, Sonenberg N A role for the elF4E-binding protein $4 \mathrm{E}-\mathrm{T}$ in $\mathrm{P}$-body formation and $\mathrm{mRNA}$ decay. J Cell Biol. 2005;170(6):913-24.

\section{Publisher's Note}

Springer Nature remains neutral with regard to jurisdictional claims in published maps and institutional affiliations.
Ready to submit your research? Choose BMC and benefit from:

- fast, convenient online submission

- thorough peer review by experienced researchers in your field

- rapid publication on acceptance

- support for research data, including large and complex data types

- gold Open Access which fosters wider collaboration and increased citations

- maximum visibility for your research: over $100 \mathrm{M}$ website views per year

At $\mathrm{BMC}$, research is always in progress.

Learn more biomedcentral.com/submissions 